\title{
LAPURDUTI
}

Euskal ikerketen aldizkaria | Revue d'études basques |

Revista de estudios vascos | Basque studies review

$7 \mid 2002$

Numéro VII

\section{Zubereraren idazkeraz : ortografia, fonetika eta fonologia}

Jean-Baptiste Coyos

\section{OpenEdition \\ Journals}

Édition électronique

URL : http://journals.openedition.org/lapurdum/1088

DOI : 10.4000/lapurdum. 1088

ISSN : 1965-0655

Éditeur

IKER

Édition imprimée

Date de publication : 1 octobre 2002

Pagination : 201-219

ISBN : 2-86781-321-2

ISSN : $1273-3830$

Référence électronique

Jean-Baptiste Coyos, «Zubereraren idazkeraz : ortografia, fonetika eta fonologia », Lapurdum [Linean] 7 | 2002, Sarean emana----an 01 juin 2009, kontsultatu 19 avril 2019. URL : http://

journals.openedition.org/lapurdum/1088; DOI : 10.4000/lapurdum.1088 


\title{
Zubereraren idazkeraz : ortografia, fonetika eta fonologia
}

\author{
Jean-Baptiste COYOS
}

IKER UMR 5478 CNRS

\section{SARRERA}

Zuberera euskalki bat dela aspaldidanik onartua da. Mendeen zehar zenbait idazlek zubereraz idatzi dute eta orain gero eta gehiago dira zubereraz idazten dutenak, batez ere pastoral testuak. Denborarekin zubereraren idazkera aldatu da. Artikulu honetan aztertu nahi genuke zertan den oraiko zubereraren ortografia eta zein diren horren ahozko mintzairarekilako loturak ${ }^{1}$.

\subsection{Euskaltzaindiaren erabakiak euskalkien idazkeraz}

"Arantzazuko Biltzarreko prestatu zuen txostenean, Euskara Batua euskara idatzirako zela mugatu zuen Koldo Mitxelenak » (Euskaltzaindia, 1998 : 1). «Ezin-bestekoa. il-edo-bizikoa (sic), dela uste dugu euskera batasunbidean jartzea nahi eta behar dugun batasun hori, lehen urratsetan behintzat, euskera idatziarena, izkribuzkoarena da » (Mitxelena, 1968 : 203). Artikulua honetan zehar, 1968an Arantzazun Mitxelenak Euskaltzaindiari aurkeztu zizkion idazkerazko eskabide batzu aipatuko ditugu. Oraiko zubereraren idazkeran onartuak izan dira. Ber bidean ibiliz, bere 1978ko Bergarako biltzarrean, Euskaltzaindiak erabaki garrantzitsu batzu hartu zituen idazkerari buruz: "Zein da Euskaltzaindiaren jarrera euskalkiei eta toki bateko hizkerei buruz? Adierazpenean esaten da Euskaltzaindia horiek lantzearen alde dela baina beti ere ortografia eta hizkuntzaren azpiegitura zainduz » (1979: 101). Eta gai hori zaila zela bazakian : «Beste aldetik, puntu hau garrantzitsua dela ez da dudarik, zeren gaur tiroak Euskaltzaindiari hortik heldu baitzaizkio. Hots, euskalkien eta herriko euskararen izenean » (ibid.).

Alabaina euskalkien ortografia bera eta bakarra izan behar da Euskaltzaindiaren ustez: "Euskara hizkuntza bat da eta ez hizkuntza asko. Hizkuntza osoarentzat ortografia bat onartua denez gero, begien bistan da ortografia bakar hori erabili behar dela bai euskalkietan eta bai euskara batuan ere... Hizkuntzaren barnean ortografia bat baino gehiago erabiltzeari kaltegarri deritza Euskaltzaindiak » $(1979: 104)^{2}$. Hogei urtez goizago, ez zen Henri Gavel-en iritzia, adibidez: "...le souletin a autant de droit que n'importe quel autre dialecte à être pourvu d'une orthographe qui tienne compte de ses particularités propres » (1960 : 213). Euskaltzaindiaren ustez euskararen oinarri batu bat badugu : « Euskalkien axaleko ñabarduren gainetik hor da hizkuntzaren muin sakon eta iraunkor hori, hizkuntzaren oinarri batua, eta hori da beti gogoan eduki behar duguna, baita euskalkiak lantzen direnean ere » (1979:

' Eskerrak emaiten dizkiet Junes Casenave-Harigile-ri, Jean-Louis Davant-i testu honen lehen bersioari buruzko haien ikusmoldea eman didatelakotz. Horrek ez du erran nahi anas ados direla idatzi dudanarekin. Eskerrak ere Xarlex Videgain-i bere irakurtze ernearengatik.

Laburdurak : adib. $=$ adibidez, bat. = batua, ik. =ikus, zub. = zuberera. Adibideetan hitzen forma ortografikoa hizki etzanean agertzen da, fonetikoa [ ] artean eta fonologikoa / / artean.

2 Halerik ere ber orrialdean Euskaltzaindiak salbuespen zenbait onartzen ditu "linguistika lanetan », " toki jakin bateko euskara den bezala jaso nahi denean ", " herri mailako literatur mueta batzuetan » eta bertsolaritzan (1979: 104). 
105). Bainan Euskaltzaindiak azpimarratzen zuen, ber aldian, ez zuela ahoskatzea arautu nahi : "Erabaki hauek grafiari begira daude eta oraingoz ahoskatzeaz ez da ezer adierazten » (1979:92).

Horretan da erronka zeren eta, dakigun bezala, ortografiak eta ahoskatzeak lotuak baitira, nahi ala ez. Eta ortografiak ez baldin badu ahoskera manatzen, eragintzen du halere. Ber denboran ere ez dugu ahantzi behar idazkera ahozko mintzairatik etortzen dela eta ez kontrakoa.

\subsection{Zubereraren ortografiaren finkatzeaz}

Euskaltzaindiak bere 1999ko Zuberoako herri eta herritarren izendegia-n behin betiko Zuberoako herri eta herritarren izenen ortografia finkatu ditu ${ }^{3}$. Gauza on bat da eta erabaki mota horiek Euskaltzaindiaren zereginetan sartzen dira. Lan hori interesgarria da ere bai zeren eta hautatu diren epaibideak zehaztuak baitira. Alderantziz izen berezi horiek bazterturik, jakin behar da Euskaltzaindiak ez duela deus erabaki zubereraren idazteko molde egokiaz, hobeki erranik zubereraren ortografiaz. Gorago aipatu Bergarako erabakiek euskalki oroendako balio dute. Bainan dakigun bezala salbuespen bat bada aspaldidanik zubereraren idazkeraz, $\ddot{u}$ hizkia erabilia baita [y] ahozkatzen denean. Eta Euskaltzaindiak grafema hori ez du baztertu ${ }^{4}$.

Haatik hogei bat urtez geroztik bi zuberotar euskaltzainak, idazle batzu, zenbait aditu lan horri lotuak izan ziren eta orai erraiten ahal dugu zubereraren ortografia finkatua dela. « Euskara Batuaren araberako grafia berria hedatu da zubereraz ere, Euskaltzaindiak Bergarako Biltzarrean, 1978an, erabaki zuenaren arabera. Logikoa eta errexa da grafia berri hau » (Davant, 2001 : 8). Horrek ez du erran nahi zubereraz idazten dutenek denek artoski erabiltzen dutela, bainan erabiltzen ez dutenak guti dira.

\subsection{Artikulu horren helburuak}

Zuberera euskalki bakoitza bezala ezaugarri lexiko, sintaxiko baita ere fonetiko eta fonologiko batzuen bidez bereizten $\mathrm{da}^{5}$. Artikulu horren helburuak dira oraiko zuberotar grafiari buruzko zenbait gogoeta egitea, grafi berri horren mugak argitzea, zuberotar ahoskeraren eta zuberotar idazkera arautuaren arteko loturak aurkeztea. Finkatua den oraiko grafia eta euskalkiaren fonetika, fonologiaren elkarrekilako harremanak marraztuko ditugu. Hortako deskribapen fonetiko-fonologiko bat beharrezkoa $\mathrm{da}^{6}$. Laburbilduz eta xehetasunetan sartu gabe, «fonologia » hitzak zer erran nahi duen adierazteko hori da ikerlearen lana: aztertzen duen hizkuntzan bilatzen du zein hotsek balio bat duten, beste zenbaitek ez dute baliorik (adib. [œ] hotsak ez du baliorik euskaraz). Hizkuntzaren balio duten hotsak fonologikoak dira hizkuntza honetan.

Gerla baten piztea ez da gure nahia, bainan bai ikustea zertan den duela guti finkatua izan den zubereraren ortografia. Finkatze hori xantza bat da eta idazletarik gehienek onartu dute.

Hizkuntzen ortografia ez dela osoki fonetikoa edo fonologikoa ezaguna da. Bainan ortografia bakoitza hurbiltzen da guti gora behera hizkuntzaren fonetikatik (edo fonologiatik). Dakigun bezala frantsesaren ortografia hurrun da bere fonetikatik. Lan honi esker ikusiko dugu beraz euskarak, hemen hain

${ }^{3}$ Horri esker adibidez Ündüreine herriko sargietako eta irteeretako seinaleak Ündüreine eta Ündüreïne idatzirik ez ditugu gehiago ikusiko, eginik izan den bezala duela guti.

4 Euskalkien ahoskeran [y] bokala onartu du : "... sei bokaleko sistema duten Iparraldeko euskaretan <u>ren ahoskera biak onartzen dira ([u] eta [ü]) hala eskatzen duten hitzetan eta baita ere euskalkiaren erabilera zainduan » $(1998: 2,1$. araua).

${ }^{5}$ Ikus adibidez Zuazo, 1989.

${ }^{6}$ Zuberotar fonemen aurkezpen orokor batez ikus Coyos, 1999, 2. atala. 
xuxen zubererak, idazkera fonetiko bat, fonologiko bat duenetz, maiz erraiten den bezala. Artikuluan zehar beraz ikusiko dugu hobekixago zer adiera duen gorago aipatu genuen Davant-en «logika» hitzak (1.2). Alderantziz ez dugu kasu eginen hitzen etimologiari, ez ere zubereraren kondairari.

Junes Casenave-Harigile-n zubererari buruzko 1989ko Hiztegia Français-Eüskara eta 1993ko Hiztegia II Eüskara-Français baliatuko ditugu, eta bai ere Piarres Charritton-en 1997ko Hiztegia Dictionnaire hiztegia, hori konparaketa egiteko zubereraren ortografia "Iparraldeko batua "-ren eretzean? Casenave-Harigile-n hiztegiak hartzen ditut bakarrak baitira oraiko ortografiarekin argitaratuak direnak. Zubererazko aitzineko hiztegi orokorra Lhande-n 1926koa zen. Geroztik lexiko batzu ez ziren argitaratu baizik. Casenave-Harigile-n bi hiztegi horiek zinez baitezpadakoak bilakatu dira beraz, hutsune handi bat baitzen. Zubereraren oraiko ortografiaz lekukoak bilakatu dira. Txomin Peillen-ek dion bezala Casenave-Harigile-n lehen hiztegiaz, 1989koaz : « Hiztegi arauemailea da... beraz Züberoeraren idazteko, euskalki horren arauzkatzeko egina da, ez linguistentzat ${ }^{8}$ " (1989, Aitzin hitza); eta horrentzat hartuko dugu artikulu honetan. Halere erran behar da hiztegi horiek leku emaiten diotela euskara batuari, ikusiko dugun bezala, batua zubereratik bereizi gabe ${ }^{9}$.

Beraz, hiztegi horietako grafiazko aukera batzu argitaratzea artikulu honen helburuetarik bat da ere. Bainan behin betikotz lerro hauen irakurleak jakin dezan tresna horiek bazter gabeko balioa dutela neretzat eta zubererazaleentzat.

\section{ZUBERERAREN GRAFIAREN BILAKAERAZ}

Zubereraren grafiaren bilakaera osoki aurkeztu nahi gabe, aro nagusien idazteko molde batzu aipa ditzagun. Jakina da Juan deTartas-en Ontsa hiltzeko bidea (1666) lehen zuberotar liburua ez dela ${ }^{10}$. Tartasek berak zion: " Ene euskara, eta lengajia eztakit aprobatia izanen denéz, bai, ala ez, badü orotarik zerbait, Zuberoak, Basa-nabarrek, eta Lapurdik eman drauko zerbait, baina ez oro» (1666 - 1975: 7). Tartasek ezagutzen zituen hizkuntza « guztien orthographien nahasmendu izugarri bat egiten duelako... oso guttitan salbu, ez $\mathrm{du} / \ddot{u} /$ eta $/ u /$ orthographiaz bereizten » (Eguzkitza, ibid., XX).

Erran behar da Athanase Belapeyre-ren Catechima laburra... ez dela ere egiazko lehen zuberotar liburua $(1696-1983)^{11}$. Pello Agirrek testu zaharrago bat aurkeztu du 1676ko Pronus singulis diebus... testu anonimoa, behar bada Belapeyrek idatzirik (A.S.J.U., 1998). Idazleak ou digrama erabilzen du /u/ transkribatzeko eta $u$ grafema $/ \mathrm{y} /$ fonemarendako, $c / \mathrm{k} /$-rendako bai ere $/ \mathrm{s} /$ rendako $i$ eta $e$ aitzinean, $f / \mathrm{s} /$ fonemarendako $a$, $o$ eta $u$ aitzinean, $/ z /$ eta $/ z /$ herskari txistukari ahostunak ez ditu bereizten, herskari hasperen ahoskabeak ez

${ }^{7}$ Laburdurak: 1989koa, Hiztegia eta 1993koa, Hiztegia II. Aitzin solasean Charritton-ek idazten du bere hiztegiak « Eskola Hiztegia » izena duela (XIV), bainan azalean Hiztegia Dictionnaire ez da baizik deitzen. Casenave-Harigile-k egiten ez duena, Charritton-ek aipatzen du hitzak zein euskalkitik etortzen direla $B, G, N B, N G, N L$ eta $Z$ (zuberera) laburdurak erantsiz (XLVXLVII), beharra baldin bada.

${ }^{8}$ Haientzat Lhanden hiztegia egokiago da.

${ }^{9}$ Hori buruz hori da Junes Casenave-Harigile-k idatzi didana : « Ene Hiztegia II. egin nizün, ez xiberotarra baizik emaiteko, bena ere batua; hori zen egin zeitaden galtoari ihardesteko: beharrezkoa zela gero eta gehiago irakurten baita batuaz idatzi egünkari, astekari, agerkari eta libürü ere. Arren, prefosta, zerbait baliagarri, ez haatik linguistika lan bezala ».

${ }^{10}$ Ikus atarikoaren X[X-XXII, orrialdeetan Andolin Eguzkitzak egiten dituen Tartasen grafiari buruzko oharrak.

11 Ikus aitzin solasean Jean-Louis Davant-ek egiten dituen oharrak Belapeyre-n grafiaz (13-18 orr.). 
ditu bereizten ere $t h / \mathrm{t}^{\mathrm{h}} / \mathrm{salbu}, \mathrm{h} /$ hasperena idazten du $h$-ekin, orain bezala $\tilde{n} / \mathrm{n}$ / fonemarendako ez du erabilten bainan in, etab. Hots, guti gora behera frantsesaren idazkera. Hiru mendez idazle guztiek eginen duten bezala, hitzaren azken bokalaren hersketa $-a$ aitzinean irudikatzen du : adib. gure $+a>$ gouria, orain gurea [gúja].

Bi mende geroago, 1848an, Archuk frantsesetikako grafia bat erabiltzen zuen oraino eta badirudi bere grafia ez zela biziki landua : "Archuren testuan erabat ezinezko gertatzen da $u$-ren eta $\ddot{u}$-ren artean bereiztea, bietarako... $<u>$ grafiaz baliatzen baita... Bokalarteko $-r$ - bakunak zubereraz galdu ohi dira... La Fontaineren alegien itzulpen honetan, bilakabide hauei dagokielarik, egoera aski nahasia da » (1848 - 1990, Ricardo Gómez-en hitzaurrean : 16-17).

Hamar urte geroago, Emmanuel Inchauspé-k, euskal fonologia kontutan hartuz, zubererarena barne ere, grafia argi eta guti gora behera bikoiztasunik gabea erabilten zuen: ou /u/-rendako eta $u / y /$-rendako, herskari hasperen ahoskabeendako $p h, t h, k h, t t$ eta $l l$ hizki bikoitzak bustidurendako, $\tilde{n}, y / \mathrm{d} /$ bustiaren orde, $c h$ frantsesez bezala /j/ idazteko, etab. (I858: XI-XII). Jakin behar da lan hori hizkuntzalari batena zela. Frikari txistukari ahostunendako, halerik ere, grafema berizirik ez zuen hautatu eta beraz /3/ ez zuen baizik bereizten $j$-ri esker ${ }^{12}$. Louis Gèze-k ere bere Eléments de grammaire basque, dialecte souletin... liburuan Inchauspé-ren grafia erabili zuen (1873). Horien ondotik, XX. mendeko hastapenean, Jean-Baptiste Constantin -ek $u$ eta ou, ch, $i l l, m b n b$-ren ordez, etab., erabilten zituen (1926 - 1996, Patri Urkizu-ren aitzin-solasean : XV).

Zuberotar grafiaren historia zirriborro labur hau bukatzeko eta oraikoa aztertu baino lehen, aipa dezagun Pierre Lhande-k bere hiztegian erabilten zituena (1926: XXXI). Orduko Euskaltzaindiak ortografia onartua zen : $\ddot{u}, u, x$, $t x, p h, t h, k h, / \mathrm{t} / \mathrm{d} / \mathrm{eta} / \lambda / \mathrm{kontsonante}$ bustiendako marratxo batekilako hizkia, $\tilde{n}, r$ dardakari bakunarentzat eta $\tilde{r}$ dardakari anizkunarentzat. Bi grafema baizik ez ziren faltatzen Iparraldeko euskalkien fonologiari osoki moldatu izateko: zuberotar $/ z /$-ak eta /z/-ak ez zuten hizki berezirik, jakinez zubereraren bokal sudurkariek ez zutela ere grafema berezirik bokalea $+n$ taldeak aparte (adib. handi [hấdi] bainan ahate [ãhấte]).

Bere Zuberoako idazle zenduak liburuan, Jean-Louis Davant-ek grafia hori eta oraikoa buruz buru ezarten ditu lehen aldikotz argitaratu den Clément de Jauréguiberry (1895-1965)-ren «Mort pour la France » testuan, bi grafiez idaztez (2001 : 138-153). Davant-ek dio: «...lehenik agertzen dut ortografia xaharrean... Zuberera nola behar den ahoskatu dastatuko du..., fonetika hurbilagotik errespetatzen baitu. Baina logikaren araberakoa da bigarrena, sinplea, erreza » (2001 : 139). Jauréguiberry-k, ordu arte idazle guztiek egiten zuten bezala, hitzen aldaketa fonetikoa markatzen zuten : eskian (138) / esküan (139, Davant), emaztiak (138)/ emazteak (139, Davant), onduan (144)/ ondoań $(145 \text {, Davant })^{13} \ldots$ Beherago ikusiko dugun bezala, 4 . atalean, txandaketa hori morfologia fonetikoan sartzen da: bokalen ahoskatzea kanbiatzen da testuinguruaren arabera, $-a$ aitzinean. Beraz grafia hori fonetikoa da fonologikoa baino.

12 « 23 le $\mathbf{S}$, dans le dialecte souletin, a un son plus doux dans un petit nombre de mots tels que losa, arrosa, jesus, guisa (sic) ... 30 le $\mathbf{Z}$ a le son du $c$ doux du français... dans certains mots tels que aizina... le son du $z$ français " (1858: XII).

13 Idazteko molde hori ediren daiteke lekuka Patrick Queheille-n aurtengo Lau Bürü testuan : tradizionik tradizioneak-ren orde (14), nijan eta nin ber orrialdean (28)... Hori sar daiteke Euskaltzaindiak onartzen dituen salbuespenetan, herri mailako literaturan (ikus gorago 2. oharra). 
Gainera ohartzen da Davant-ek beste zenbait hitzen grafia kanbiatzen duela zubereraren oraiko grafiari jarraikiz : untsa (138) ontsa-z (139) ordezkatzen du, hun (144) hon-ez (145), ikhusi (140) ikusi-z (141), ürhats (140) ürrats-ez (141), bueita (144) boita-z (145), ixker (146) ezker-rez (147), etab. Kasu horietan ez dugu ahoskera manatzen duen testuinguru fonetiko berezirik. Ortografia berriak hautu bat egin du, hautu horrek ez du gauza handirik ikusteko zubereraren fonetikarekin edo morfologia fonetikoarekin, bainan bai grafia berdintasunaren bidearekin, Euskaltzaindiak agintzen zuen bezala (ikus 1.1). Davant-ek aipatzen zuen erraztasuna da euskara batua irakurtzen badakitenentzat. Gehiago aztertu gabe, hori ondoko ataletan eginen dugu, ohar daiteke ere zubereraren grafia berria " logikoa »-ren, batasunaren bururaino ez 'dela joaiten osoki : adibidez idatzi behar genuke heldü eta ez heltü [hélty] onartua den bezala, saldü [sáldy] edo bildü [bíldy] idazten den ber ; egüngo eta ez egünko [egý́ko] egiten den bezala ; gazna [gazná] onartua izan da gasna-ren edo gazta-ren ordez, etab.

Henri Gavel-en iritziaz, " substituer purement et simplement à cette orthographe traditionnelle celle qui est en usage pour le labourdin..... serait le défigurer, en lui donnant l'aspect d'un parent pauvre que l'on aurait affublé d'un costume fait pour un autre membre de la famille " (1960:213), lotsa hori egiaztatu da pixka bat. Horrek ez du erran nahi zubererak bere ezaugarriak galdu dituela, jakinez ortografia bat hitzarmen bat baizik ez dela. Bainan, ortografia berri horrengatik, zuberera beste euskalkietarik eta euskara batutik bereziki hurbildua da bere itxura berriaz. Jean-Louis Davant-ek oraiko grafiaz idazten du : «Berria, Gau-Eskolek eta Zuberoako ikastolek batuari hartu die ta (sic) zubereran ezarri. Logikaren araberakoa den baina zuberotar ahoskeratik urruntzen da zinez, hau ez baita batukoa " eta "irakur errexa da, bereziki zuberotarrak ez direnentzat. Baina zuberera bere fonetikatik urrun dezake. Haren eta batuaren arteko euskalki berri bat ote digu sortuko » (1993:41). Nere ustez egia da grafia berri honek zuberera ere kanbiatuko duela zeren eta hiztun gazteek eskolan ikasten baitute zuberera familian eziez. Eta erran nezake " logika » hitz hori ez dela hain egokia, grafia hori «bateragarria » dela lehen lehenik.

Bainan iritzi hori gehiago azaldu gabe, ikus dezagun zein diren gaurregungo grafemak, hizkiak eta horiekin joaiten diren fonemak.

\section{OHAR BATZU ORAIKO ORTOGRAFIAZ : FONEMEN ETA GRAFEMEN ARTEKO ELGARRIZKETAK}

Zubereraren fonemak eta haien grafemak ondoko bi tauletan aurkezten ditugu. Ikusten den bezala, zenbait fonemak bi idazteko manera baditu. Erran behar da ere bokal sudurkariak ez direla beti markatuak. Alderantziz, fonema batzuek ber grafema badute. Orokorki oraiko ortografia sinplea da, Davant-ek erraiten zuen bezala (ik. 2). Bainan ahozko mintzairarekilako harremanak argitu behar ditugu erabaki aitzin, ikusteko ere « logikoa » denetz. 


\subsection{Zubereraren fonemak eta horien grafemak}

\section{Bokalak}

\begin{tabular}{|l|c|c|c|c|c|c|c|c|c|c|c|c|}
\hline Grafema & $a$ & $e$ & $i$ & $o$ & $\begin{array}{c}u \\
o\end{array}$ & & $\begin{array}{c}a \\
\text { an }\end{array}$ & $\begin{array}{c}e \\
e n\end{array}$ & $\begin{array}{c}i \\
i n\end{array}$ & $\begin{array}{c}u \\
\text { on }\end{array}$ & $\begin{array}{c}u \\
\text { un }\end{array}$ & $\begin{array}{c}u \\
u\end{array}$ \\
\hline Fonema & $/ \mathrm{a} /$ & $/ \mathrm{e} /$ & $/ \mathrm{i} /$ & $/ \mathrm{o} /$ & $/ \mathrm{u} /$ & $/ \mathrm{y} /$ & $/ \mathrm{a} /$ & $/ \tilde{\mathrm{e}} /$ & $/ \mathrm{i} /$ & $/ \overline{\mathrm{o}} /$ & $/ \overline{\mathrm{u}} /$ & $/ \overline{\mathrm{y}} /$ \\
\hline
\end{tabular}

\section{Kontsonanteak}

\begin{tabular}{|c|c|c|c|c|c|c|c|c|c|c|c|c|c|c|c|c|c|c|c|c|}
\hline $\begin{array}{l}\text { Gra- } \\
\text { fema }\end{array}$ & $b$ & $d$ & $d d$ & $f$ & $g$ & $h$ & $j$ & $k$ & $l$ & $\begin{array}{l}i l \\
l l\end{array}$ & $m$ & $n$ & $\begin{array}{c}i n \\
\tilde{n}\end{array}$ & $p$ & $r r r$ & $s$ & $t$ & $\begin{array}{l}i t \\
t t\end{array}$ & $x$ & $z$ \\
\hline $\begin{array}{l}\text { Fone- } \\
\text { ma }\end{array}$ & $/ \mathrm{b}$ & $/ d$ & $\begin{array}{c}/ \mathrm{d} \\
/ \\
14\end{array}$ & $\begin{array}{c}\text { /f } \\
/\end{array}$ & $/ \mathrm{g}$ & $\begin{array}{c}\mathrm{h} \\
/\end{array}$ & $\begin{array}{l}13 \\
1\end{array}$ & $\begin{array}{l}\mathrm{k} / \\
\mathrm{k} \\
\mathrm{h} /\end{array}$ & $\begin{array}{c}/ I \\
/\end{array}$ & $\mid \overline{|K|}$ & $\begin{array}{l}\text { / } \\
\mathrm{m}\end{array}$ & $\begin{array}{l}\ln \\
/\end{array}$ & $/ \mathrm{n} /$ & $\begin{array}{l}/ \mathrm{p} / \\
\mathrm{p} \\
\mathrm{h}\end{array}$ & $/ r /$ & $\begin{array}{l}/ \mathrm{s} / / \\
7 /\end{array}$ & $\begin{array}{l}/ \mathrm{t} / \\
/ \mathrm{t} \\
\mathrm{h} /\end{array}$ & $/ 1$ & 15 & $\begin{array}{l}\mid s / \\
|z|\end{array}$ \\
\hline
\end{tabular}

\subsection{Bokal sudurkariak_: $/ / /, / \tilde{\mathbf{y}} /, / \tilde{\mathbf{\varepsilon}} /, / \tilde{\mathbf{u}} /, / \tilde{\mathbf{o}} /, / \tilde{\mathbf{a}} /$}

Bokal sudurkariak fonetika ingurumen desberdinetan agertzen dira eta ondorioz horien ahoskera desberdina da pixka bat ingurumenaren heinean. Horiek dira mota ezberdinak:

- Bokala + kontsonante sudurkaria Atzeranzko asimilazioa $/ \mathrm{n} /$ aitzinean : adib. handi [hấdi], [handi] eziez. / $/ \mathbf{u} / \sim / \widetilde{o} /$ oposaketa fonologikoaren adibidea : /hû́tto/ hontto « gozoki » /ốddo/ onddo. Hitzaren azken silabako $/ \mathrm{n} /$ ahoskatzen da : egün (85) [égyn]. Ortografiak sudurkaritzea erakusten du $n$-ren bidez. Frantsesaren historian gertatu zen bezala, bokala sudurkaritzen da $/ \mathrm{n} /$ kontsonante apiko-alabeolare sudurkariaren aitzinean.

- Kontsonante sudurkaria + bokala Aurreranzko asimilazioa $/ \mathrm{n} /$ edo $/ \mathrm{m} /$ gibelean : ama [ắmã] edo [áma], arrano [aranú́]. Ingurumen fonetiko honetan sudurkaritzea ez da beti egina eta ortografiak bokal sudurkariak ez ditu erakusten.

- /h/ ondoan Adib. ahate [ãhắte] latinetik anas, anitis; xahü [Jấhỹ] «xahu, garbi ». Gisa berean, kontestu honetan sudurkaritzea ez da beti gauzatzen eta ortografiak ez du seinalatzen. Alderantziz ohe [óhe] sudurkaritzerik gabe ahoskatzen da.

- Azken silabaren bokalaren sudurkaritzea Adib. karru / karroi

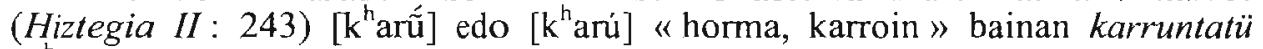
[k haruntáty] «karroindu » kontsonante sudurkariarekin ; biarnesetikako maileguetan : arrazoin / arrazu (30) [arazú́] « arrazoin » edo [arazú] (ikus ere Lafon, 1962: 88). Goiko oharrak kasu honetan ere aplikatzen dira eta ohar daiteke zubereraren ortografian - oin taldeak $-\boldsymbol{u}[\tilde{\mathrm{u}}]$ edo [ú] emaiten duela.

Bokal sudurkariekin ez dut uste beste grafema baten asmatzeak balio duela. Pentsa dezakegu bokal sudurkari hiru azken motak galduko direla, frantsesez ez baitira ahoskatzen kontestu horietan. Erran behar da ere ahoskatze txandaketa badela hiztunen arabera, sudurkaritzea automatikoa ez delarik. Asma dezakegu sudurkaritze fonologikoa lehen sudurkari motarentzat ez dela baizik izanen denborarekin, kontsonante sudurkariaren galtzeak aitzineko bokalaren sudurkaritzea erakartez.

\footnotetext{
${ }^{14}$ Herskari sabaikariendako irakurgarrigoak diren [t] eta [d] marka fonetikoak hautatuko ditut nazioarteko alfabeto fonetikoko [c] et [f] markak eziez.
} 


\subsection{Aitzineko bokal expainkaria : $\ddot{u}=/ \mathbf{y} /$}

Sarreran erran dugun bezala, /y/ fonemak hizki berezi bat badu, $\ddot{u}^{15}$. [y] hotsa Oihenart-en garaian, XVII. mendean, erabilia zen Zuberoan, berak aipatzen duen bezala eta Leizarraga-ren garaian ere René Lafon-en ustez ${ }^{16}$.

$/ y /$ baizik ez da erabilten testuinguru zahar batzutan /u/-ren ordez, bainan bai ere frantsesetikako maileguetan $/ œ /-n$ ordez, azken fonema hori euskal fonologian ez delakotz sartzen : frantsesez [traktór] tracteur, zubereraz [traktýr] bilakatzen da ; frantsesez [bór(ə)] beurre " guri », zubereraz [býra]...

/y/ fonemarekin ez da "fonema zalantzarik » edo "fonema gorabeherarik» (ikus 4.1) : / $/$ / edo /o/ ez dira nehoiz ahoskatzen $/ \mathrm{y} /$-ren ordez. Hona oposaketa fonologikoaren adibide bat: /hyr/ hür (bat. hur) $\sim /$ hur/ hur (bat. ur) $\sim /$ hor/ hor.

\subsection{Gibeleko bokal ezpainkaria : $o=/ 0 /$ eta $/ u /$}

2. atalaren bukaeran aipatzen genuen oraiko grafia bategilea gauzatzen da $/ \mathrm{u} /$ bokal ezpainkariarekin. Kasu batzutan $[\mathrm{u}]$ ahoskatze denean o grafema erabiltzen da $u$-ren ordez : moldatü (Hiztegia II : 309) [muldáty]; tronpatü (416) [trú́(n)páty], Etxartek trunpatü (2002:22) ; lano (265) [lanhú]; ohoin (337) eta uhoin (429) [uhúp] ... /u/ /o/ oposaketa fonologikoa da : /lu/ lu «baldoki » (Hiztegia II : 279 «lo 1) tempe; cf. lu;2) sommeil...») //o/lo.

Ez da txandaketarik hitz horiekin, [u] ahoskatzen da eta ez [o] ahozko mintzairan. /o/-tik / $\mathrm{u}$ /-rako aldeketa hori ez da oraikoa ${ }^{17}$. Nere ustez $u$ idatzi behar genuke hitz mota horrendako, beste euskaldunek ahoskera jarraikitzen duen grafia hori uler lukete ere trabarik gabe.

On / hon / hun. On hitza idazteko Casenave-Harigile-k hiru grafia eskaintzen ditu Hiztegia II-n : hun (191), hon (187) eta on (342). Batasunari jarraikiz on hirugarren grafia, $h$ - gabekoa, hautatu behar luke; zubereraren bidean ibiliz hun izan daiteke, [hun] ahoskatzen delakotz. On-etikako eratorpenean erran behar da ontsa (345) badugula, [úntşa] edo [û́tsa] [h] gabe ahoskatzen dena. Hunki ez da emanik, honki (188) eta ongi (344) baizik, [hṹki] ahoskatzen den ere. Etxart-ek hunki idazten du (2002: 8).

\subsection{Leherkari gangarkari hasperen ahoskabea : /h/ $h$ eta $/ \mathbf{n} /, / \mathbf{n} /, / \mathrm{N}, / \mathbf{r} /$ $+/ \mathrm{h} /$ bikoteak}

- /h/ $\boldsymbol{h}$ Dakigun bezala $h$ grafema Euskaltzaindiak onartua izan da, euskal alfabetoko hizki bat da. Zuberoan $/ \mathrm{h} /$ egiazko fonema bat da, frantsesan ez izanik ere, eta ahoskatzea ez da galtzen. Bere Hiztegia II-n, usaiako aurkezteko manera erabiliz, Casenave-Harigile-k bi ortografia eskaintzen ditu, batuarena eta zubereraren bat: adib. hur zubererarena (192) eta ur batuarena (433), jakinez [hur] ahoskatzen dela. Hobe ere, aize (12) emaiten ditu eta haize (bat.) (162), [ájse] ahoskatzen dena. Aldi honetan $h$ - gabeko grafia berezi bat badugu, aize, Zuberoako ahoskerari egokia dena.

- Kontsonantea $+/ \mathbf{h} /\langle H$-rik ez da idatzitako itxitura osoa duten kontsonanteen ondoan...Baiona-n erabaki zenez, ezta ere bestelako

\footnotetext{
${ }^{15}$ Jean-Baptiste Constantin idazleak $u$ hizkia erabilten zuen $\ddot{u}$-ren ordez (1926 - 1996)

${ }^{16}$ "(...on peut tenir pour certain que ü existait déjà en souletin » (1962:83). Erran nahi du XVI mendean. Lafon-ek zion : "Ainsi, si $\ddot{u}$ est devenu en souletin un phonème distinct de $u$, dont $\mathrm{il}$ était d'abord une variante combinatuire, c'est qu'il s'est formé de nouveaux $u$, les uns provenant de $o$ devant nasale, les autres, plus récents, provenant de la réduction du groupe úa» (1962:92).

${ }_{17}$ René Lafon-ek dio: "La tendance à changer $o$ en $u$ s'est manifestée avec plus de force qu'ailleurs en bas-navarrais oriental et en souletin. Elle a dû affecter d'abord les $o$ suivis d'un $n$ ou d'un $m \ldots$... (1962:91).
} 
kontsonanteen hatzean: erho, belhar, unhatu eta horien gisakoetan » (Mitxelena, $1968: 207$ ).

Kasu honetan azpimarratu nahi dut silaba egitura ez dela ongi aztertua izan. Silaba mozdura hasperena baino lehen egiten da eta beraz kontsonantea eta $/ \mathrm{h} /$ ez daude ber silaban. Herskari hasperen ahoskabeen kasuan ez gaude, maiz erraiten den bezala: $/ \mathrm{p}^{h} /, / \mathrm{t}^{h} /, / \mathrm{k}^{h} /$ fonemekin hasperena herskadurari lotua da (ik. 3.6). Orain aztertzen dugun kontestuan, kontsonante baten gibelean, $/ \mathrm{h} / \mathrm{ez}$ da galtzen ari, dirudienez. Alderantziz $/ \mathrm{p}^{\mathrm{h}} /, \mathrm{t}^{\mathrm{h}} /, \mathrm{k}^{\mathrm{h}} /$ fonemen hasperena ez da beti gauzatua.

- /nh/n : lano (Hiztegia II : 265) [lánho] ahoskatzen da.

- /nh/ $\tilde{\boldsymbol{n}}$ : eine (87) « neke », [ع́phe] ahoskatzen da eta ez [Éjne].

- /lh/ l : alor (17) [álhor] ; elesta (89) [elhésta] ; ilun (bat.) (209) / ülün (431) [ýlhyn]. Zal(h)e (459) [sálhe] (Etxart-ek zalhe, 2002: 96) eta zal(h)ezal(h)ea (460) izenen $h$-a mako artean idatzia da. Aterabide hori ez da hain argi : erran nahi ote du bi grafiak egokiak direla, $h$-ekin eta $h$ gabe ?

- /rh/ r: marranta (296) [marhăta], ürre (436) [ýrhe]... Kontsonante sudurkari bakuna ahoskatua ez baita (ik. 3.10), [h] ahoskatzen da idatzia ez izanik ere : er $(h)$ i (100) «behatz » [éhi] eri (100) [Ej]; ero (101) [Érho] eho « hil, erail » (86) [Ého]; orit (349) [óhit], Etxart-ek orhit (2002: 66) ; soro (395) [sóho]...

- Diptongoa $+/ \mathrm{h} /: / \mathrm{nh} /, / \mathrm{nh} /, / \mathrm{lh} /$ eta $/ \mathrm{rh} /$ bi fonema taldeekin auher « alfer » (37) [áwher] edo oihan (357) [ójhan] kasuan bezala gaude. Diptongoa eta $/ \mathrm{h} / \mathrm{ez}$ dira ber silaban. Auher-ren edo oihan-en grafiek ahoskatzea errespetatzen dute.

Oraiko zubereraren ortografian, $/ \mathrm{n} /, / \mathrm{n} /, / \mathrm{N}$ edo $/ \mathrm{r} / \mathrm{n}$ ondorengo $/ \mathrm{h} /$ fonema ez da markatua, erran nahi baita $/ \mathrm{nh} /, / \mathrm{nh} /, / \mathrm{lh} /$ eta $/ \mathrm{rh} /$ taldeetan. Nere iritziz izan behar daiteke, diptongo ondoan eginik den ber, alhor, elhesta, lanho, ülhün..., lehen idazten zen bezala, oposaketa ageraraziz : ala juntagailua $\sim$ alha (Charritton : 10), aran « ibar» arhan fruitua, eri $\sim$ erhi «behatz ». Hemen ere, zuberotar ez diren euskaldunek ahoskera jarraikitzen duen grafia hori uler lezakete trabarik gabe.

\subsection{Herskari hasperen ahoskabeak: $/ \mathrm{p}^{\mathrm{h}} / p, / \mathrm{t}^{\mathrm{h}} / t, / \mathrm{k}^{\mathrm{h}} / \mathrm{k}$}

Lafonek eta Mitxelenak ez zuten ohartu herskari hasperen ahoskabeak egiazko fonemak direla zubereran, bereziki duela guti mailegatuak izan diren hasperenik gabeko hitzei esker ${ }^{18}$. Bikote edo hirukote batzu badira : /bala/ bala (arma) $\sim / \mathrm{p}^{\mathrm{h}}$ ala/ pala (lanabes) $\sim / \mathrm{pala} /$ pala (pilota) ; / mót $\mathrm{t}^{\mathrm{h}} \mathrm{o} /$ moto « motto,

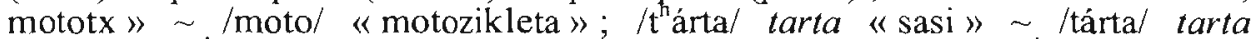
(pastiza); /k aráty/ karratü « kerra » / karáty/ « karratu »;/mãk áty/ mankatü « zauritu » /mãkáty/ « hutsegin », etab.

Oraiko zubereraren idazkeraz Euskaltzaindiaren araua onartua izan da: « $H$-rik ez da idatzitako itxitura osoa duten kontsonanteen ondoan (aphez, athe, ekharri, etc.) ") (Mitxelena, 1968: 207). Halerik ere, Zuberoako herri izen batzutan Euskaltzaindiak hasperenaren idaztea onartu du, estakuru emaitez izen bereziak direla : Atharratze, Atherrei, Ithorrotze (ikus Euskaltzaindia, $1999: 7$

${ }^{18}$ Ikus Coyos: 1994. Lafonek zion: «En basque, à la sonore s’oppose, suivant les parlers et les mots une sourde aspirée ou une sourde non aspirée : jamais les deux... les occlusives sourdes aspirées et les sourdes non aspirées ne constituent pas des phonèmes, mais des variantes phonétiques » (1948: 60). Haren ondotik Mitxelenak erran lezake : "Tenemos pues el hecho teóricamente interesante de un rasgo que reúne todas las condiciones necesarias para diferenciar significados, sólo que al parecer distingue ninguno » (1961 - 1985 : 208, 2. oharra) 
eta 15$)^{19}$. Gorago erran dudan bezala, finkatuak izan diren Ainharbe, Arhane, Olhaibi, Zunharre, Zunharreta grafiak ez dira ber kasuan fonologiaren ikusmoldeaz, bi fonema direlakotz (kontsonantea + h) (ik. 3.5).

$/ \mathrm{p}^{\mathrm{h}} /, / \mathrm{t}^{\mathrm{h}} /$ eta $/ \mathrm{k}^{\mathrm{h}} /$ herskari hasperen ahoskabeak galtze irriskuan daude. Hasperena ez idazteko argudioa izan daiteke ez dela beti ahoskatzen, « fonema zalantza » batengatik desagertzen ari dela (ikus 4.1). hitzaren arabera zenbait hiztunek herskaria hasperen gabe akoskatzen baitute, bereziki gazteek. Adib. : piper " biper » [p íper] edo [píper]; arto [árt $\left.{ }^{\mathrm{h}} \mathrm{o}\right]$ edo [árto]; ikasi [ik áşi] edo [ikási]... Eta ez baldin badira idazten, segur da herskari hasperendunak gero eta gehiago galduko direla, kontutan hartuz bigarren atalean azpimarratzen genuena : gazteek zuberera eskolan ikasten dutela familian eziez.

\subsection{Sabaikariak, kontsonante bustiak : /n/ $/ \tilde{n} / \mathrm{in}, / \lambda \mathrm{il} / \mathrm{ll}, / \mathrm{t} / \mathrm{it} / \mathrm{tt}, / \mathrm{d} / \mathrm{dd}$}

Kontsonante bustiei buruz hori da Euskaltzaindiak erabiki duena laburbilduz : « 1. Euskaltzaindiak ontzat hartzen ditu $\tilde{n}, l l, t t, d d$ eta $t x$ kontsonante palatalen grafiak balio adierazkorra duten kasuetan, hala nola andereño, haurño, ñabar, llabur... Maddalen... hitzetan agertzen direnak. 2. Egituraren bidez, aurreko $i$ - bokala dela medio, leku batzuetan sortu diren palatalizazioetarako, ordea, -in-, -il-, -it- eta -ind- erabili behar dira, palatalizaziorik egiten ez den eskualde eta alderdietan bezalaxe, hala nola baina, mutila... eta abar... 3. Halaber erdaritaratikako hitzetan, despalatalizazioaren bidez sortu den grafia ontzat harturik, hala nola Espainia, gaztaina, ... 6. Ortografia lege hauek berdin balio dute edozein euskalkitan eginikako izkribuetarako ere... » (Euskaltzaindia, 1979: 91-92). Erabaki horiek osoki aplikatuak izan dira oraiko zubereraren idazkeraz.

- /n/ eta /in/: fonema ezberdinak Bokal ondoko [in] bikotea [n] ahoskatzen da Zuberoan. Zubereraz hots bakun bat badugu, [ת] sudurkari sabaikaria. Adib. : artzain (Hiztegia II : 32) [artsáj] eta ez [artsájn]; ohoin (337) [uhún] eta ez [ohójn]; üinürri «xinaurri » (429) [ynhýri] eta ez [yjnýri]. Bustidura hori, [in] $>[n]$, aspaldin gauzatu daiteke.

Bainan oposaketa fonologiko bat da zeren eta $/ \mathrm{j} /$ egiazko fonema bat da zubereran, /in/ bi fonemen bikotea delarik: /mína/ mina « min (mugatua)» /mínal miña (miñaberje) " mahasti »; [hájna] harena (izenordaina) [hájna] hariña « hondar ». Txardina «s ardina» [t]ardína] edo [ [ardína] ahoskatzen da eta ez [t fardína].

Kasu honetan idazteko molde bakar bat badugu, in, [n] eta [in] bi hots eta fonema desberdinentzat.

- ñ grafemaz Euskaltzaindiak bustiduraren idaztea ez du onartu Zuberoako herri batentzat baizik, $\tilde{n}$ erabiliz: Urdiñarbe. Salbuespen horren argibidea hona da: " $\tilde{N}$ galtzen ez düan bakoitza Urdiñarbe da, busti gabeko formaren (Urdinarbe) ahoskeratik saihesteko » (Euskaltzaindia, 1999 : 6). Eta beraz ere * Urdiinarbe grafia saihesteko nere ustez.

Izen arruntei buruz, ohartzen da $\tilde{n}$ onartua dela Hiztegia II-n zenbait hitzen lehen hizkiaz 331. orrialdean : ñabar, ñabo..., - $\tilde{n} i$ atzizki tipitzailea erabilia da ere. Urdiñarbe kasuaz bezala, $i$ ondoan $\tilde{n}$ hautatua da in-en ordez: erregiña (104) « erregina », espartiña « espartin » (111), iñazi « tximist » (209) [ijhhási],

19 Txomin Peillenek hola argitzen zuen : «Il est regrettable que le basque qui se parle désormais de plus en pius avec l'accent et la phonétique française ou espagnole ait perdu presque partout sa demière originalité, les consonnes $l n, r h, n h, p h, t h, \tilde{n} h, l l h, k h$ absentes des autres langues européennes. Ce phénomène est hélas irréversible mais qu'au moins les noms de lieux en gardent le souvenir » (2000). Bainan, hola aritzez, ortografian ez onartzeak horien desagertzea zalutzen du. Pronus... lehen zuberotar testuan (1676) th idatzia zen bainan ez ph eta $k h$ (ASJU, 1998, XXXII-1 : 8). 
ttipiñi (331)... Bestenaz *erregiina, *espartiina, ${ }^{*}$ iinazi, ${ }^{*}$ ttipiini genituzke ${ }^{20}$. Ii digrama ez da onartua zubereraz hala nola batuaz. Aldi berean ohart dezagun Espainia (111) [Espánja] ahozkatu behar lukela idazkera jarraikiz eta ez [espána] egiten den gisaz.

Laburbilduz, kontestuaren heinean bi grafema desberdin erabiltzen dira ber fonemarentzat $/ \Omega /$, in edo $\tilde{n}$.

$/ \lambda, / t /$ eta $/ \mathrm{d} /$ ondoko kontsonante bustientzat ber egoera da. Mitxelenaren eskabidea onartua izan da : "Hobe, ordea, il, in idaztea soil-soilik, aski bait litzake hori edozein ohar dedin $i$ hori dela medio, bere euskalkian, hurrengo $l$ eta $n$ bustiak direla...» (1968: 208). Azpimarratu behar dugu ere kontsonante sabaikari horiek, hots txikikaritako erabiliak izanik ere, egiazko fonemak direla.

- I $\lambda /$ il / ll, alboko sabaikaria $/ \lambda$ / alboko sabaikaria idazteko bi grafema baditugu, il eta $l l$. Ll zenbait hitzen lehen hizkiaz onartua da. Adib.: lloba

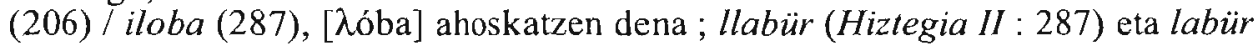
(262) [ $\lambda$ ábyr] ez da baizik ahoskatzen. Iloba bigarren grafia hori irakur daiteke [ilóba] eta $[\mathrm{n}] \sim[\mathrm{in}]$ oposaketaz bezala, [il] $\sim[\lambda]$ oposaketa fonologikoa badugu. Adib. : ilar (206) [ílhar] ahoskatzen da eta ez [ $\lambda$ ar] edo [ $\lambda$ har].

- / $\mathrm{t} /$ it / $t$ t herskari sabaikari ahoskabea Beraz / $t /$ (nere idazteko maneraz) sabaikari ahoskabea idazteko, /c/ nazioarteko fonetika alfabetoan, bi grafema baditugu ere, it eta $t t$, fonema batentzat $/ t^{21}$ eta it grafema bikotea bi fonemarentzat, / $t$ / eta /it/. Aita [ájta] ahoskatzen da eta ez [áta].

- /d/ herskari sabaikari ahostuna Herskari sabaikari ahostunak, /d/ nere idazteko maneraz, grafema bat baizik ez $\mathrm{du}, d d . / \mathrm{d} / \sim / \mathrm{d} /$ oposaketaren adibide bat : onddo (343) [ốdo] ondo (343) [ốdo]. Alabaina id digrama ez da onartua izan sabaikaritzea markatzeko, «logika »-k manatuko zuen arabera. Dd hori hitz leku oroetan ahoskatzen da, hitz bukaeratik kanpo ${ }^{22}$.

- Sabaikarien idazkeraren erraztea Sabaikari horiek egiazko fonemak dira, balio adierazgarria dutelarik. $\tilde{N}$ eta $t t, d d, l l$ digramak ez dira onartuak hitz leku oroetan, aspaldidanik erabiliak baldin badira ere. Busti gabeko formaren ahoskeratik saihesteko hautatuak dira: lillüra «lilura » (278) [ $\lambda \mathrm{i} \lambda$ ýra] eta ez iliilüra, ttattit « mutu eta higitugabe » (471) [tatít] eta ez itaitit,... Bainan, ikusi dugun bezala, irakurtze nahasketa kasu batzu badaude oraino.

Beraz, nere iritziz, zubereraren ortografia argiago eta sinpleago batetarantz joaiteko $\tilde{n}, \| l$ eta $t$ behar genituzke erabili kasu oroetan $[n],[\lambda]$ eta [t] idazteko, $d d$-z egina den bezala.

\subsection{Frikari txistukari ahostunak : $/ z / z, / z / s, / z / j$}

/s/ eta /s/ frikari txistukari ahoskabeak eta $/ z /$, $/ z /$ frikari txistukari ahostunak ez dira bereizten hizkien bidez: $z$ erabilia da/s/ eta $|z|$ fonemak idazteko, $s / \mathrm{s} /$ eta $/ \mathrm{z} /$ fonemak idazteko. Haatik / $/$ txetxekari ahostunak bere hizki proprioa badu, $j$, eta beraz $/ \bar{y}$ txetxekari ahoskabeak berea ere, $x$.

Ohartzen ahal da grafia berezi bat onartua izan dela zubereraz zenbait hitzentzat : gazna (140) [gazná] eta gazta (140, bat.), gasna-ren ordez, ber gauza ezne (119) [Ezné] eta esne (111, bat.), bi izen oxitono horiek txistukari hozkaria badutela euskalkian.

/s/ eta /z/ horzkariak, /s/ eta /z/ apiko-albeolareak ( « rétroflexes » hobe errana, mihia itzultzen baita), / $/$ eta $/ 3 /$ txetxekariak egiazko fonemak dira

${ }^{20}$ Alderantziz, zubereraz arrain-en idazteko, Pierre Lhande-n áraiñ grafia hiperzuzenketa forma bat daiteke : $\mathrm{i}+\mathrm{j}(1926: 70)$.

${ }^{21}$ Txomin Peillen-ek, adibidez, Petiarra idazten du (2001: 3) Zuberoako eskualdeaz, Euskaltzaindiak Pettarra onartu duenean (1999:23), [petára] eta ez [petjára] ahoskatzen dena.

22 Mitxelenaren eskabidea ez da onartua izan : " Ba dirudi, beraz, kontsonante-ondoan $d d$-ren ordez ere erabil ditekeala, beste aldekoek egiten duen gisan : onjo $=$ onddo $»(1968: 208)$. 
zubereran. Adib. : sapata (461) /sapáta/ zaparta (461) /zapárta/ ; xoratü "zoratu » (451) / foráty/ jorratï (234) /3oráty/. Haatik ez dut uste grafema berezi baten asmatzeak balio duela / $z /$ eta / $/$ /-rentzat. Zubereraren idazkeraren historioan zehar ez bait dira sekula idatziak izan grafema berezi batez, [z] eta [z]-ren ahosdura kontestuala baita zenbait aldiz ere : ikasi (204) [ik ási] bainan ikasle (204) [ik ázlle], balios «baliotsu » [baljús] bainan baliosa (mugatua) [baljúza]... Erran behar da ozenketa hori automatikoa ez dela : Nola « haiz » hiz [his]? Ontsa hiza [hísa]?

\subsection{Txistukari afrikatuak : /ts/ $t z, / \mathrm{ts} / t s, / \mathrm{t} \backslash / t x, / \mathrm{d} z / j$}

$/ \mathrm{ts} / t z, / \mathrm{ts} / t s$ eta $/ \mathrm{t} \downarrow / x$ horskari ahoskabe afrikatuak maiz erabiltzen dira zubereraz, egiazko fonemak dira eta hiztunek ez dituzte nahasten, zaharrek bederen. Adib. : bakoitx / bakoitz (Hiztegia II : 45) [bák ot.] eta ez [bakójts]; hanitx / hanitz (165) [hánit]] eta ez [hánits], haritx / haritz (165) [hajt]] eta ez [haríts], etab. Zergatik ez hemen -tx digrama baizik ezartea edo bi ortografiak onartuak baldin badira ez aipatzea - $t x$ dela zuberarena ? Zuberotar ez diren euskaldunek errazki konpreni lukete.

Zenbait mailegutan /dz/txistukari ahostun afrikatua ahoskatzen da frantsetikako $x$ [ks/gz]-ren ordez: examen « azterketa » [edzamén]; berdin lanjer " galbide » [lãdz̨r]. Mailegu mota horiek emanik ez dira Hiztegia $I I-\mathrm{n}^{23}$. Grafema berezi baten asmatzea behargabekoa daiteke.

\section{$3.10 / \mathbf{r} / \sim / \mathbf{r r} /$ : dardakarien oposaketaz}

Gaurregungo zubereran iduri du $/ \mathrm{r} /$ eta $/ \mathrm{rr} /$-ren arteko oposaketa neutraldua dela leku oroetan: hitz hasieran dardarkaririk ez baita agertzen mailegu batzuetarik kanpo (adib. runt «biribil » [runt]), hitz barnean bokal arteko /r/ bakuna ahoskatzen ez delakotz (hari [haj]) eta hitz bukaeran ere hitz oposaketarik faltaz.

Badirudi ahoskatze desberditasunik ez daitekela hitzen dardakarien artean : adibidez har [har], dardakari bakunarekin, eta harri [hár(r)i]), dardakari anizkunarekin. Bereizketa hori galdua da. Dardakari anizkuna aipamen azkartzeko tresna bat da bereziki, perpausari bizi emaiteko.

\section{MORFOLOGIA FONETIKOAZ ETA LEXEMEN GRAFIAZ - AHOZKO MINTZAIRA : PERPAUSEAN DIREN HITZEN ORTOGRAFIA}

\subsection{Hitz baten idazkera desberdinak- Adiera baten hitz desberdinak - Zubererarena eta batuarena}

Ikusi dugun bezala 3. atalean zehar, bere Hiztegia II Eüskara-Français-n Junes Casenave-Harigile-k zuberotar eta batuazko grafiak emaiten ditu hitz batentzat, edo « Iparraldeko batua »-zkoa bederen.

Halaber bi edo hiru jatorri ezberdinezko hitz emaiten ditu zenbait adierarentzat : larunbat (Hiztegia $I I$ : 268) emanik da erabilia ez izanik ere, bainan bai ere neskanegün (326) zuberotar formetarik bat; neskenegün [ncskenégyn] beste ahoskera mota bat ez da edireiten (/a/ eta /e/ arteko fonema zalantzaren ondotik). Lore (281) eta lili (277) emanik dira : lehen forma ez da erabilia Zuberoan.

Batzutan Zuberoako hitza ez da emanik, arramaitz (erromanikotikako aurrizkiarengatik segurki), eta bai batuarena, ekain (87); halaber arrapostü (Charritton arrapostu) ez da emanik eta bai erantzüte. Alderantziz hitz arrunt batek, ardu (25) [ardú] adibidez, bere «batua »-zko formak ez ditu : ardo,

${ }^{23}$ Charritton-ek lanjer emaiten du (1997: 329), balios ere (29). 
arno; halaber zieta-rekin (469), plater (369) emanik da bainan ez azita edo

Ber jatorrizko hitzekilako adibide: arrazoin (bat.) eta arrazu (30) emanik dira (Etxart-ek arrazu, 2002: 64), ber definizioarekin, bainan bigarrena baizik ez da ahoskatzen [arazú] edo [arazú] (ikus 3.2). Halaber baino (44) (bat.) eta beno (56) [béno] hitzarekin : bigarren ahoskatzea erabilia dena da eta ez *[bájno] edo *[bajnó] ${ }^{25}$; berdin huin (191) eta oin (339) (bat.) : [huj]; ilun (207) (bat.) eta ülün (431) : [ýlhyn]; mende (300) (bat.) eta mente (301) : [mếte]. Hiztunen arabera beste ahoskatze horiek "manexak" dira. Batzutan forma arrunt bat falta da : ïili [ýky] ez da emana baina bai üili (429) eta uli (431) (bat.). Beheragoko lerroaldeetan ikusiko dugu laburzki zein morfologia fonetiko kontesturengatik hitz horien zuberotar ahoskera gertatzen den.

Zenbaitetan, hitzaren ondoan of. laburdurak irakurlea bigarren formara itzularazten du. Adib. : berdin (57) « semblable, égal ; cf. bardin », erran gabe bardin (47) [bárdin] "1) égal ; 2) également ; 3) lisse, uni ", dela zuberotar ahoskera. Alderantziz, zenbait aldiz bi formak emanik dira $c f$. laburdura gabe : eüskara (115) eta üskara (439), [yskká] ahoskatzen dena eta ez [Eqskará]. Eüskara grafiarekilako eratorpena aberatsa da 115. orrialdean; aldiz üskaratikako emanik diren hitzak guti dira, azken hori zuberotar forma izanik ere. Halaber hur(a) (192) : « eau; cf. ur; oro hur: tout trempe » eta ur(a) (433). Urte (438) eratorpena emanik da definizio horrekin: "1) année; 2) inondation», hurte (193) «1) déluge ; 2) crue » emanik delarik ere. Jakinez [hur] ahoskatzen dela zubereraz eta ez [ur], hurte grafia egokia daiteke urte [úrt'e] izenarekilako bikoiztasuna kenduz.

Zenbait hitzekin hiru grafia izan daitezke. Adib. : alkar (17) « cf. algar eta elkar ». Alkar [álk ${ }^{\mathrm{h}}$ ar] ahoskera arruntena definiziorik gabe da; beste biek aldiz bat badute : " mutuellement » (algar, elkar), "l'un l'autre, les uns les autres » (elkar).

Egin ondoan errexago da noski bainan hitzaren ondoan $(Z)$ zuberera edo (ahos.) ahoskera, (bat.) batua edo (NL) nafar-lapurtera laburdurekin hobekixe aurkeztua izanen ziren hiztegi horretako hitzak, batuaren ortografien emaitea ere hautatua izanez geroz. Zein diren zuberotar, nafar-lapurtar, hots Iparraldeko akoskera desberdinak jakiteko Lhande-n hiztegia ordezka-ezina da oraingoz.

\section{- Zuberoako ahoskatze desberdinak}

Gorago nabaritu dugu Zuberoan berean zenbait hitzek ber ahoskera ez dutela hiztunaren arabera edo lurraldearen arabera. Eta hori maiz gertatzen da. Adib. : arrastiri (Hiztegia II: 29) «arratsalde», bainan [aristí] eta [arestí] baditugu ere bai, Etxart-ek arrestiriko (2002:54):/a/, /e/ eta /i/ fonemen arteko zalantza bat bada ; ühaitz « mendi ibai » (428) [yhájts], bainan [yhéjts] ere bada berriz /a/ eta /e/ fonemen zalantzarengatik; buxi " puxka, zati » (74) edo muxi (318): $/ \mathrm{b} /$ eta $/ \mathrm{m} /$ fonemen arteko zalantza badugu. Azpieuskalkiak bereiz daitezke zenbait hitzen ahoskatzearen arabera.

Ahoskera desberdina baldin bada Zuberoako lurraldearen arabera, fenomeno hori "fonema zalantza » deituko dugu («flottement de phonèmes" frantsesez).

${ }_{25}^{24}$ Lhande-k zieta (C.) emaiten du, orokorra bezala (1926 - $\left.1938: 1086\right)$.

${ }^{25}$ Davant-en 1983ko hautua hori zen : « $E I$-ren ordez $A I$, beste eüskalkiek $A U$ dien (sic) aditz formetan : dait (daut), eta ez deit... ; bai eta baina, baino (bena, beno)... beste eüskalkietan bezala » (1696-1983, 18). Kasu hauetan bi formekin Cazenave-n hautuak zuberotar ahoskatzeari leku emaiten du. Ez da sekula ahoskatzen [dajt] bainan [dejt] ; Casenavek deit emaiten du (Hiztegia II : 524). 


\section{- Hiztunaren ahoskatze desberdinak}

Ohartu behar dugu ere hitz batzuek bi ahoskatze badutela ber hiztunarentzat, gorago fonema zalantza lerroaldean aipatu ditugunak zenbait aldiz ere. Adib. : alkar [álk ${ }^{\mathrm{h}} \mathrm{ar}$ ] eta algar [álgar], matela [mat éla] eta maxela [maéla] (matel eta mazela, 298), etab. Fonema zalantza bat da bainan hiztun batentzat.

Kasu horretan, bakoitzaren aldakuntza hori « fonema gorabehera » deituko dugu (« fluctuation de phonèmes » frantsesez).

\subsection{Hitzaren ahoskatze aldaketak testuinguruaren arabera perpausean}

Ahozko mintzairan ohikoa den bezala, zenbait aldaketa fonetiko desberdin sor daitezke hitz juntaduran. Fenomeno horiek aipa ditzagun laburzki, motak denak aurkeztu gabe. Bainan lehenik erran behar da oraiko ortografia egokiena dela kontestutik kanpoko hitzen ahoskeraren grafia hautatuz eta perpausetan gertatzen den ahoskera baztertuz. Erabaki hori logikoa da, Davant-en hitza errepikatuz (ik. 1.2). Perpausetan hitzaren azken bokala edo kontsonantea aldatzen da ondoko mugatzailearengatik edo ondoko hitzaren lehen hotsarengatik. Halere hitzaren idazkera ez da kanbiatzen, bera baldin bazen gisaz.

- Bokal hersketa e > i : bide [bíde], bide bat [bidébat] bainan bidea [bidí(j)a] eta ez bidia, eta beraz bidean [bidín] eta ez bidian edo bidin lehen idazten zen bezala ${ }^{26} .0>\mathbf{u}$ : lo eta loa [lú(w)a] (mugatua), ez lua...

- Ezpainkaritzearen galtzea y > i : Badüzü [badýsy] / Badïzüa? [badysi(j)a] (galdera); xahü (bat. xahu), xahüa [Jãhi(j)a] (mugatua).

- Kontsonante aldaketa Adib. : sos « diru " [\$os], sasa (mugatua) [şóza] : txistukariaren ozenketa sortzen da (ik. 3.8) ; non sar? [núntsar], txistukaria afrikatua bilakatzen da, etab.

- Bokal, kontsonante edo silaba murrizketa

Ikusi dugun bezala ahozko mintzairan bidean [bidin] ahozkatzen da, ber gisaz beharrian [beharín], bat bera [bapéa], zonbat «zenbat» [sumát], hamabost [amúst], egüerditan [eguértan], etab. Bidean [bidín] kasuan adibidez, hersketaz gain hiatoa kendu da.

Xuxen den bezala oraiko idazkerak morfologia fonetikozko gertaera horiek ez ditu kontutan hartzen, hitz batek grafia bat baizik ez duen printzipioa jarraikiz.

\subsection{Morfologia fonetikozko agerpenak hitzen barnean}

Halaber hitz barnean morfologia fonetikozko gertaera desberdin sor daitezke. Ikus dezagun zein diren xehetasunetan sartu gabe.

\section{- Bi bokal koropilatzea}

Ahozko mintzairan silaba barneko hiatoaren kenketa maiz gertatzen da, jakitez diptongoak ere onartuak direla. Adib. : joan (232) [3un] ahoskatzen da, Etxart-ek jun idazten du (2002 : 82) ; eüskara (115) / üskara (439) [yská] ikusi genuena (4.1), etab.

\section{- Atzeranzko asimilazioa}

Gibelaldeko bokalaren aitzinatzea gerta daiteke eta erran behar da kasu horietan ez dela fonema gorabeherarik (ik. 4.1) : ülün (431) [ýlhyn] ahoskatzen baldin badu, hiztunak ez du ilun (207) [ílhyn] edo [ilún] (bat.) ahoskatuko ;

\footnotetext{
${ }^{26}$ Euskalkien ahoskeran Euskaltzaindiak kanbiamendu horiek onartzen ditu : " <ea, oa> idazten diren bestelako ahoskerak egoki eta zuzen direla gainerako hizkera mailetan (hala nola : etxia, etxie ; geruago, telefonua eta kidekoak » $(1998: 2,2$ a. araua).
} 
berdin ütürri (441) [yt $\mathrm{t}^{\mathrm{h}}$ ýri] eta itürri (216), ützüli (441) [ytsýli] eta itzuli (217), etab. Asimilazio mota hori maiz gertatzen da Zuberoan, sistematikoa ez izanik ere.

Casenave-Harigile-k bi grafiak emaiten ditu. Gure ustez aterabide hona da jakinez asimilazioarekilako ahoskera dela arruntena.

\section{- Aurreranzko asimilazioa}

Adib. : üili (429) eta uli (431, bat.) emanik dira bainan ez üilü [ýdy] ahoskera arruntena.

\section{- $A \ddot{u}[$ aj] diptongoa}

$A u$ diptongo zaharretik etortzen den [aj] diptongoa aü idazten da. Ezpainkaritzearen galtze hori perpausean gertatzen den aipatu genuena da (4.2). Adib. : gaü (140) (bat. gau) [gaj] eta ez [gay], Niko Etxart-en pastoralean gaiko (2002, azalean) idazten du. Halaber caüzo (38) (bat. auzo) [ájso]; gaüza (140) (bat. gauza) [gájsa], etab. Ez banaiz tronpatzen, [ay] beraz aü diptongoa ez da edireiten zubereran; alderantziz [aw] au eta [aj] ai diptongoak maitztasun handikoa dira. Beraz onartua izan den aü grafia horrek aspaldiko ahoskera oroitarazten du. Ez dakit ai grafia egokiago daitekenetz, batuaren grafiatik urrunduko daiteke.

\section{- Bokal arteko dardarkari bakunaren erorketa : sinkopa}

Gaurregungo zubereran $/ \mathrm{r} /$ eta $/ \mathrm{rr} /$-ren arteko oposaketa neutraldua da leku oroetan (ikus 3.10). Bokal arteko / $r /$ bakunaren galdera bat bada eguneroko ahoskeran, silaba bat kenduz. Adib. erori (102) [joj], bi dardakari bakunak bokalen artean daudelarik ez dira ahoskatzen. Bainan erorten [jórten], bigarren dardakari bakuna ahozkatzen da bokal bat eta kontsonante baten artean delakotz.

Xuxen den bezala $r$ bakuna berrezarten da idazten denean, hori « logikoa» da. Kantuetan, pastoraletan, $r$ bakun hori ahoskatzen da neurtitzak behar baldin badu. Zuberotar hiztunek badakite $r$ bat badela: hori [hoj] bainan hortan [hórtan].

$\boldsymbol{r} \boldsymbol{h}$ taldearekin berezitasun bat sortzen da: dardarkari bakunaren erorketa gertatzen da eta beraz [h] baizik ez da ahoskatzen. Adib. : er(h)i "behatz » (100) [éhi] eri (bat.) eri [Ej], orit « oroit» (349) [óhit], soro (395) [sóho]... hiztunek $[\mathrm{r}]$ eta $[\mathrm{h}]$ bereizten dute, dardarkari bakuna kenduz bi bokal artean baldin bazegoen bezala.

Kasu honetan zein ote daiteke idazkera egokiena? Behar bada $r h$ bikotearekilakoa, orhit, orhit, sorho.

- /n/ sudurkariaren eta /V/ albokoaren gibelean den herskariaren ez ozentasuna

[n] edo [1] + herskaria kontsonante taldearekin herskariaren ozentasuna ez da beharrezkoa. Halerik ere Hiztegia II-n bi idazteko moldeak edireiten ditugu. Adib. : heldu (177, bat.) eta heltü (177) [hélty] ; mende (300) eta mente (301) [méte], Etxart-ek mentetan (2002: 34); zango (460) eta zanko (461) [sắk o]. Halere igante (199) [igấte] baizik ez da emanik, igande grafia ez emanez; halaber egünko (85) [egý́ko] eta ez egüngo edo egungo.

Uste dut herskari ahoskabearen hizkiarekilako grafia nahiko daitekela. Zuberotar ez direnek ulermen arazorik gabe irakur lukete. Kasu honetan ere, beste grafia, herskari ahostunarekilakoa, bat. laburduraz aipatu behar zezakeen.

\section{- Azentuaren lekuaren balioaz}

Aurkezpen labur hau bukatezeko, fonemekin deus ez duen ikustekorik fenomeno bat aipa nahi nuke. Ontsa ezaguna da zubereraz azentua hitzen edo hitz taldeen azken bigarren silaban ezarten dela gehienetan. Arau horri esker azentuaren lekuak balio ukan dezake zenbait kasutan. Adib. : biga [bíga] zenbakia biga [bigá] « miga, bigantxa » (mugatua), - $a$ bokalez bukatzen diren 
hitz mugatuek azentua azken silaban badute; badakit [badákit] (ez alokutiboa) $\sim$ badakit [badakit] (zuka), etab. ${ }^{2}$

Azenturik ez baita euskararen grafian, oposaketa fonologiko horiek ez ditugu markatzen ahal. Bainan ez da arazo handirik, testuinguruari esker ulermena trabatua ez baita eta oposaketa kasu horiek bakan direlarik.

\section{ONDORIOA : ZUBERERAREN ORTOGRAFIA EGOKIENA? IKUSMOLDE BAT}

\subsection{Aurkezpen honen mugez}

Aurkezpen hori hortan uzten dut. Uste dut datuetarik gehienak eta garrantzitsuenak aurkeztu ditudala. Bainan aitortu behar dut aditz jokatua ez dudala aztertu. Horri buruz ere zer erran bada, ohartuz ahoskatzeko arauak berak direla.

Honela zein da idazkera egokiena, erran deikü, Peillenek bezala Hiztegiako aitzin solasean (1989), edo erran deigü, Casenave-Harigile-k bezala (Hiztegia II, 1993: 524) ? Hor ere bi hautuak badira : ahoskatzen den bezala idaztea [éran déjky] edo "logika» jarraikiz azpimarratzea gü 1. pertsona plurala dela, gü [gy] bera denean ahoskatzen baita ; halaber zaikü «zaigu » (Etxart, 2002, 12) [sájky] edo zaigü (Hiztegia II : 493), bainan haigü (Etxart, 2002, 58) [hájky] ? Hait "haut » (Etxart, 2002: 60) [hajt] edo haüt (Hiztegia II : 502) ? Dialarik (Etxart, 2002 : 36) [djalájk] edo dïialarik?

Nündüzün "nintzan (zuka)" (Hiztegia $I I: 488$ ) [nỹ(n)dýn(t)syn] ahoskatzen da, bigarren [y]-ren ondoan sudurkaria sortzen da asimilazioaz (4.3). Hemen, gorago ez dugun aurkeztu beste fenomeno bat da: [n] eta [1] ondoan txistukari frikari bat dagoena afrikatzen $\mathrm{da},[\mathrm{s}]>[\mathrm{ts}]$ (nündüntzün). Bukatzeko, silaba murrizketa adibide bat: badïtük «badituk» [badýtyk] ahoskatzen da bainan maiz ere [batýk].

Hemen «logikoa»-ren bidea jarraikiko genuke, deigü, nündüzün edo badütük idatzez. Bainan erran behar dugu erabakiaren hautua ez dela beti hain nabari.

Zuberoako azpieuskalkiak ez ditugu aipatu ere, ahozko mintzaira erabatekoa baldin bazen bezala edo, hobe, aipatzen genituen ahoskera desberdinak kokatu gabe. Bainan hori beste lan bat daiteke, dialektologia ikerketa bat, eta ez zen lan honen helburuetarik bat.

\subsection{Ortografia baten ezaugarriak}

Idazkeraren azterketa bi ikusmoldez egin behar liteke : historikoa, bere bilakaera sortzetik oraikora ikertzez (ikus gure zirriborroa 2. atalean), eta sinkronikoa, erran nahi baita bere ibiltze arauak eta bere ahozko mintzairarekilako loturak ateratzez. Azken ikuspuntu hori zabaldu dugu lan honetan.

Idazkera ahozko mintzairaren ordezkaritza da, eta ez egiazko mintzaira. Horrez gain, bigarren atalean erran genuen ortografia hitzarmen bat baizik ez zela ere. Bainan hitzarmen horrek ondorio batzu baditu, horietatik garrantzitsuena da, behar bada, ortografiaren ikaste erraztasuna edo alderantziz ikaste zailtasuna. Erraztasun hori harremanetan dago ahoskerarekin, erran nahi baita ortografiaren ikastea errazago daitekeela ahoskeratik hurbil baldin bada. Hala ere baiespen hori egiaztatzeko da.

${ }^{27}$ Adibide gehiagorentzat ikus Coyos, 1999, 85-86. 
Beste ondorio bat da ortografiak ahoskera finkatzen duela, hori noski guti gora behera, jakinez hiztunak ahoskatzeko askatasuna baduela eta ortografia finkatua baldin bada ere ahoskera aldatzen dela denborarekin.

Azpimarratu behar da ere ortografiaren ukaitea hizkuntzaren ezagupen sinbolikoa dela.

Azken finean, argi da ortografia bat erabilkorra izan behar daitekeela. Pragmatikoa da izenlagun egokia logikoa baino. Hala nola ez duela balio urte hanitz iragaitea ortografia ikasteko, frantsesarenarekin egiten den bezala.

\subsection{Zubereraren ortografiaren kasua}

Zubereraren ortografia bat hautatu baino lehen oinarrizko galdera hori da: zuberera euskalki oso bat dela onartzen ote da? Hori baldin balitz, bere ortografiaz ere erakutsi behar luke, ahoskeratik hurbil izatez. Bestenaz euskara batu mota bat izan daiteke, bere ortografiaz bederen.

Euskaltzaindiak dio: "Euskara Batuaren ahoskera zaindua (EBAZ) ahozko hizkuntza estandarra izango da... Ez da Euskara Batuaren ahoskatzeko modu bakarra eta are gutxiago noski, euskalkiak ahoskatzeko era » (1998: 1). Ber gauza da idazkeraz nere ustez, zeren eta ez baldin balitz euskararen idazteko molde bat baizik, hori estandarra izan daiteke eta euskalkiek ez lukete beraz ortografiarik. Ortografiarik gabeko euskalkiak bere nortasuna ez du eskuratuko ortografiari esker bederen. Zubereraren ahoskera aldatuko da segurki, ortografia propio bat ukanik ere. Bainan nortasuna ahoskeraz lehen lehenik zaintzen baldin bada ere, zubererak beste euskalkiek bezala ez du askatasunik ukanen ortografia propiorik gabe, jakitez gero eta gehiago idazten dela. Uste dut ortografia propiorik gabe zubererak ez duela izaiterik ukanen gaurregun.

Beraz onartzen baldin badugu zubererak ortografia propio bat ukan behar duela, azterketa honen ondorio bat da zubereraren ortografia egokiena ortografia fonologiko bat izan behar dela. Eta hori egingarri da grafema berririk hartu gabe. Txomin Peillenek azpimarratzen du: « Halte à l'ignorance (sic) dans quelle langue au monde l'écriture est-elle phonétique ? » (1992). Egia da, bainan hori ez da gure gaia. Erronka da nola ortografia bakun bat egin, zuberotar fonetikatik eta batuaren ortografiatik hurbila litekeena. Garai bateko hitz forma hartuz? Bainan zein garaitik? Testuetarik lehen aipamena aidibidez ? Hiztunak ez dira etimologia adituak.

Zubereraren ortografia bakar baterako bidean traba bat badugu : zenbait hitzen ahoskera desberdinak fonema zalantza edo fonema gorabeherarengatik (ik. 4.1). Kasu horietan trinkatu behar da. Hori da Euskaltzaindiaren eta hiztegien eginbeharra.

Zubereraren ahoskeraren finkatzea ez da helburua, bainan guti gora behera euskalkiaren ezaugarriak kontserbatzea. Hortarako, grafia tresna bat izan daiteke, bakun baldin bada. Ahoskeraren begiratzea eta ortografiaren ikaste erreza izan beharko ziren bi helburuak zubereraren ortografia finkatu zenean. Horri buruz ohartaraz dezagun hizki propio bat ukaiteak ez duela hotsa begiratzen automatikoki : $s$ hizkiak /s/ eta /z/ txistukari apiko-albeolareak ez ditu kontserbatu belaunaldi gazteetan.

Beraz konponbide egokiena da, nere ustez, oraiko ahoskeratikako ortografia hurbil bat, fonologikoa guti gora behera, testuinguruak erakarriak diren ahoskera aldaketak baztertuz.

\subsection{Zenbait proposamen errazterantz}

Malgutasuna da aterabidea, zubererari askatasuna emanez ortografia propio bati esker. Horrek ez du erran nahi ortografia hori batuarenaz osoki desberdin 
izan behar dela. Eta ikusi dugun bezala 1.1 lerroaldean, Euskaltzaindiaren erabakiak, " ortografia bakar hori behar dela bai euskalkietan eta bai euskaran batuan ere », zenbait eraketa onartzen dituela (ik. 2. oharra).

Gisa batez, zubererak bere ortografia propioa eskuratu du erakaskuntzan. Aurten, adibidez, Ikas pedagogia zentroak matematikazko zenbait liburu argitaratu ditu Iparraldeko haurrentzat, nafar-lapurtar eta zubererazko itzulpenez, Jean-Louis Davant zuberotar euskaltzainak itzuliak, Euskaltzaindia hizkuntza begiratzailea delarik. Halaber Pika haur hilabetekariak bi itzulpen baditu, bata zubereraz ${ }^{28}$.

Nere iritziz, iduri luke zubereran ondoko eraketa horiek onar daitezkela, $\ddot{u}$ hizkia izan zen bezala, kontestutik kanpoko hitzen ahoskeraren grafia hautatuz. 3. eta 4. ataletan proposamen horien argibideak aurkeztu ditugu, oraiko zubereraren ortografian zuberotar fonetika ezaugarriak idazteko onartuak izan ziren berezitasunak erakustean.

- $u$ hizkia eta ez $o / \mathrm{u} /$ ahoskatzen denean : lu «baldoki », nur, trunpatu (3.4).

- $n h, \tilde{n} h, l h$ eta $r h$ hizki taldeak / $/$ ahoskatzen denez geroz eta $h$ hizkia onartua zen ber: elhesta, lanho, erhi, sorho $(3.5) . / \mathrm{p}^{\mathrm{h}} /, \mathrm{t}^{\mathrm{h}} / \mathrm{eta} / \mathrm{k}^{\mathrm{h}} /$ fonementzat erabakia ez da hain argi (3.6), ikasi edo ikhasi ? Bi grafiak onar genituzke.

- $\tilde{n}, l l, t$ leku oroetan, $d d$ onartua izan den bezala : artzañ, zuñn «zein », lloba (3.7).

- Zubereraren asimilazioen onartzea : üllü «uli » (4.3).

- Arau orokor bat zuberotar hiztegiendako: grafia bat baino gehiago emana baldin bada, zein d(ir)en zuberarena(k) aipatzea.

Proposamen horiek ez dira hanitz eta ez berri ere. Batuaren ortografiaren printzipioetarik ez dira urruntzen. Garbitze arin bat baizik ez da. Berriz ere ez dugu zuberera batuaren aurka ezarri nahi. Bakoitzak bere lekua badu ${ }^{29}$. Bainan ortografia berezi batek euskalkiaren ezaugarriak bermatzen ditu erakaskuntza erraztuz (5.3), eta bere ezagutzaren sinbolo nagusi bat da. $\ddot{U}$ hizkiari esker lehen begi kolpez irakurleak badaki zubererazko testu bat irakurtzen duela.

Nagusitu den zubereraren ortografiak batasunaren hautua egin du, berdintasunarena ez baldin bada. Soziolinguistikazko ikusmolde bat da, zenbait hizkuntzalaritzazko erabaki onekin ere. Adibidez perpausetan gertatzen diren hitzen ahoskera aldaketak baztertzea. Bainan hizkuntzalaritzazko ikusmolde batek fonologiatik hurbilago daiteken ortografia bat nahiago luke. Aipa dezagun Jean-Louis Davantek 1983 an erraiten zuena orduko zuberotar grafiari buruz : «Eta geroago eta haboro hurruntzen gira euskara idatzitik. Beste Eüzkaldünek (sic) ezin gintiroie irakur eta entelega. Beraz, libürü bat ez dirogü inprima : Eüskal-Herri osoan ez bada zabaltzen, ez dü bere büria (sic) pakatüren, ez ordaintüren » (Belapeyre, 1983 : 14). Txomin Peillen-ek idazten zuen: "Pourquoi le souletin parler (sic) par une dizaine de milliers de personnes et lu par une soixantaine, aurait-il une orthographe ghetto différente de celle des autres dialectes basques, sachant que $90 \%$ des lecteurs souletins ne sont pas souletins » (1992). Zernahi gisaz, euskaldun batek, ez xiberotarra izanik ere, $n h n$-en ordez, $\tilde{n}$ in-en ordez edo $l l i l$-en ordez edireiten baldin baditu ez da harritua izanen eta irakurtzen baldin badaki grafema horiek ere irakurriko ditu.

Egia da lexikoa eta sintaxia baditugula oraino erakusteko zuberera dela eta ez batua. Bainan lexikoa berdintzen ari da ere eta sintaxia heinbatean, euskara batuaren eraginarengatik... Beraz oreka bat ediren behar dugu.

\footnotetext{
${ }^{28}$ Pika hilabetekaria, Mendizolan argitarazlea, 28 PK, 64130 Maule (Zuberoa).

${ }^{29}$ Ikus Coyos, 2001.
} 
Gogorapen horiek polemikatik kanpo proposatzen ditut. Desiratzen ditudan «berrikuntza», aldaketa arin horiek, Euskaltzaindiaren erabakietan ez baldin badira sartzen, nik, bederen, oraiko arauak jarraikiz idatziko dut Junes Casenave-Harigile-n hiztegietako ortografia onartuz, hori baita oraiko zuberotar idazkera arautua ${ }^{30}$.

\section{Aipamenak}

Anonimoa, 1676 (1998), Pronus singulis diebus Dominicis clarè \& distinctè immediatè post Evangelium populo legendus, Pello Agirrek testu aurkeztua, A.S.J.U., 1998, XXXII-1, Donostia, Gipuzkoako Foru Aldundia, 1-46.

ARCHU Jean-Baptiste, 1848 (1990), La Fontainaren alegia berheziak, Ricardo Gómezen edizio prestatua, Oiartzun, Euskal editoreen elkartea, 277 orr.

BELAPEYRE Athanase, 1696 (1983), Catechima laburra eta Jesus-Christ goure ginco jaunaren eçagutcia, salvatu içateco, Edizio kritikoa, Jean-Louis Davantek paratua, Bilbo, Euskaltzaindia, 374 orr.

CASENAVE-HARIGILE Junes, 1989, Hiztegia Français-Eüskara Züberotar eüskalkitik abiatzez, Ozaze (Züberoa), Hitzak, 620 orr.+Erratum.

1993, Hiztegia II Eüskara-Français, Xiberotar eüskalkitik abiatzez, Ozaze (Xiberoa), Hitzak, 560 orr.

Charritton Piarres - KinTANa Xabier, 1997, Hiztegia Dictionnaire EuskaraFrantsesa / Frantsesa-Euskara, Donostia-Baiona, Elkar, 597 orr.

CONSTANTIN Jean-Baptiste, 1926 (Eskualduna aldizkarian) - 1996, Haritchabaletaren bizia, Donostia, Klasikoak, Patri Urkizuren edizioa, XVIII+1 19 orr.

CoYos Jean-Baptiste / Battittu, 1994, Des occlusives aspirées en basque, La Linguistique, 30, 2, Paris, P.U.F., 131-138.

1999, Le parler basque souletin des Arbailles - Une approche de l'ergativité, Paris, L'Harmattan, 432 orr.

2001, Souletin et batua: pour un duo plutôt qu'un duel, Madeleine de Jauréguiberry Omenaldia - Hommage, Lankidetzan bilduma 21, Donostia, Eusko Ikaskuntza, 77-84.

DAVANT Jean-Louis, 1993, Zuberotar grafiez, Argia, 1454. zka, 41. 2001, Zuberoako idazle zenduak, Donostia, Elkarlanean, 215 orr.

ETXART Niko, 2002, Ürrüti Jauregiko Peirot pastorala - Altzürükü, Maule, de Arce inprimategia, 103.

EUSKALTZAINDIA, 1979, Kontsonante busti-palatalen grafiaz Euskaltzaindiaren erabakia, Euskera, XXIV (2. aldia) - 1 Bilbo, 91-92.

1979, Kontsonante busti-palatalen grafiaz Euskaltzaindaren erabakia, Euskaltzaindiaren agiriak, Euskera, XXIV (2. aldia) - 1, Bilbo, 91-92.

1979, Euskara batua, euskalkiak eta tokian tokiko hizkerak, Euskaltzaindiaren agiriak, Euskera, XXIV (2. aldia) - 1, Bilbo, 101-106.

1998, Euskara batuaren ahoskera zaindua, Euskaltzaindiaren 87. araua, Euskaltzaindiaren webgunean, 3 orr.

1999, Zuberoako herri eta herritarren izendegia, Euskera, separata, Bilbo, 32 orr.

Gavel Henri, 1960, Revendication en faveur du souletin, Gure Herria, 25. urthea - 4 urria, Baiona, 210-213.

\footnotetext{
${ }^{30}$ Liluratu gabe nere ikusmoldea aurkezten dut jakinez duela guti finkatua izan den ortografia hor orai ontsa onartua baita. Davant-ek idazten didan bezala: "Mementoan badit beldürra jarraikizale güti dükezüla idazten düenen artean ».
} 
GÈZE Louis, 1873, Eléments de grammaire basque, dialecte souletin, suivis d'un vocabulaire basque-français \& français-basque, Bayonne, fac-similé, 1979, Donostia, Hordago, VII+ 360 orr.

IKAS, 2002, RETZ, 2001, Matematikak lantzen, CP lehen mailako 1. urteko fitxategia, 64480 Uztaritze (Lapurdi), 144 orr.

INCHAUSPÉ Emmanuel, 1858, Le verbe basque, Bayonne / Paris, Veuve Lamaignère / Benjamin Duprat, Hordago fac-similé, XII+511 orr.

LAFON René, 1948, Remarques sur l'aspiration en basque, Mélanges offerts à M. le Professeur Henri Gavel, Toulouse, Edourd Privat et Cie, 56-61.

1962, Sur la voyelle $\ddot{u}$ en basque, B.S.L., 57, l, Paris, Klincksieck, 83-102.

LHANDE Pierre, 1926 - 1938, Dictionnaire basque-français et français-basque

- (dialectes labourdin, bas-navarrais et souletin), tome I, Dictionnaire basquefrançais, Paris, Gabriel Beauchesne, LII+1117 orr.

MitXelena Luis / Koldo, 1961 (1985), Fonética Histórica Vasca, 3. a edicion, San Sebastián, Diputación Foral de Guipúzcoa, Publicaciones del Seminario "Julio de Urquijo", 596 orr.

1968, Ortografia, Arantzazu-ko biltzarrak, Euskera, Bilbo, 203-219.

PEILlEN Txomin, 1990, Aita Junes Casenave Harigileren hiztegia, Euskera, XXXV, 1, Bilbo, 231-234.

1992, A quoi bon écrire !, Le miroir de la Soule bihilabetekaria, 907. zenb., 1992/10/10, Maule (Zuberoa).

2000, Nom de noms !, Le miroir de la Soule bihilabetekaria, 1081. zenb., 2000/01/08, Maule (Zuberoa). 2001, Agur Zuberoa, Urretxu-Zumarraga, Biba Xiberua ! elkartea, 63 orr.

QUÉHEILle Patrick, 2002, Lau Bürü - Barkoxe, Ozaze, Ideki inprimategia, 59 orr.

TARTAS Jean de, 1666 (1975), Ontsa hiltzeko bidea, Andolin Eguzkitzak prestatu edizioa, Aranzazu, Edizio franciscana, 172 orr.

ZUAZO Koldo, 1989, Zubereraren sailkapenerako, A.S.J.U. , XXIII, 2, Donostia, Gipuzkoako Foru Aldundia, 609-650. 